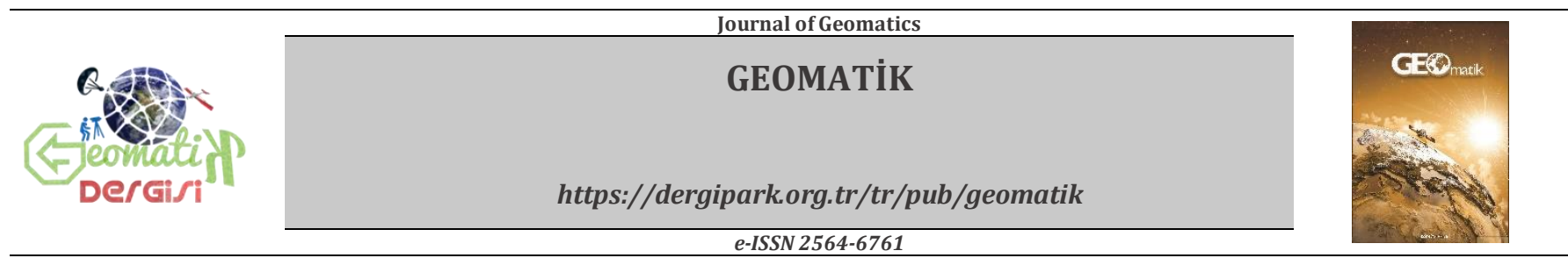

\title{
Bağıl ve mutlak (PPP) konum çözüm yaklaşımı sunan Web-Tabanlı çevrimiçi veri değerlendirme servislerinin farklı gözlem periyotlarındaki performanslarının araştırılması
}

\author{
Eren Gürsoy Özdemir*1 (D) \\ ${ }_{1}^{1}$ Bartın Üniversitesi, Ulus Meslek Yüksekokulu, Mimarlık ve Șehir Planlama Bölümü, Tapu ve Kadastro Programı, Bartın, Türkiye
}

Anahtar Kelimeler
Web Tabanlı Çevrimiçi GNSS
Değerlendirme Servisleri
MAGIC-GNSS
CSRS-PPP
AUSPOS
OPUS
Doğruluk

\begin{abstract}
ÖZ
$\mathrm{Bu}$ çalışmada, web-tabanlı çevrimiçi veri değerlendirme servislerinin farklı çözüm yaklaşımlarındaki doğruluk performanslarının incelenmesi amaçlanmıștır. Mutlak konum çözüm yaklaşımı sunan MAGIC-GNSS ile CSRS-PPP ve bağıl konum çözüm yaklaşımı sunan AUSPOS ile OPUS çevrimiçi değerlendirme servislerinin, farklı gözlem sürelerindeki $(1,2,3,6$, 12, 24 saat) ve farklı günlerdeki (DOY 048, 049, 050, 051, 052, 053/2019) verileri dikkate alınarak test edilmiștir. Bu amaçla AJAC IGS istasyonu, ITRF 2014 referans sisteminde ölçü epok koordinat verileriyle karşılaştırılmış ve elde edilen sonuçlara göre 3 saat üstü yapılan veri çözümlerinde mm doğruluğuna ulaşılmıştır. 3 saat ve altı veri çözümlerinde gerek kadastral çalışmalarda gerek birçok ölçme uygulamalarında kullanılabilecek, $\quad \mathrm{cm}$ doğruluğunda çözüm sundukları görülmüştür. Mutlak konum ve bağı çözüm yaklaşımı sunan çevrimiçi değerlendirme servislerinin yüksek doğrulukta sonuçlar elde edebildiği ve bütün çevrimiçi GNSS değerlendirme servisleri ile kolay, ekonomik ve doğru konum üretebilmenin mümkün olduğu gözlemlenmiştir.
\end{abstract}

\section{Investigation of the performance of Web-Based online data processing services that offer relative and absolute positioning (PPP) solution approach in different observation periods}

\author{
Keywords \\ Web Based Online GNSS \\ Processing Service \\ MAGIC- GNSS \\ CSRS-PPP \\ AUSPOS \\ OPUS \\ Accuracy
}

\begin{abstract}
In this study, it is aimed to examine the accuracy performance of web-based online data processing services in different solution approaches. MAGIC-GNSS and CSRS-PPP, which offer an absolute positioning solution approach, and AUSPOS and OPUS, which offer a relative positioning solution approach, have been tested by considering the data of different observation periods $(1,2,3,6,12,24$ hours) and on different days (DOY 048, 049, 050, 051, $052,053 / 2019$ ). For this purpose, the AJAC IGS station was compared with the measurement epoch coordinate data in the ITRF 2014 reference system and according to the results obtained, mm accuracy was achieved in data solutions over 3 hours. It has been determined that in 3 hours and less data solutions, they offer $\mathrm{cm}$ accuracy solutions that can be used both in cadastral studies and many surveying applications. It has been observed that online processing services that offer absolute positioning solution approach and relative solution approach can achieve results with high accuracy and that it is possible to produce easy, economical and accurate position with all online GNSS processing services.
\end{abstract}




\section{GíRiş}

Küresel Navigasyon Uydu Sistemleri (GNSS), bilimsel araştırmaların yanı sıra ticari ve ticari olmayan uygulamalarda büyük önem kazanmıș, Amerika'dan GPS, Rusya'dan GLONASS, Çin'den BEIDOU ve Avrupa'dan GALILEO dahil olmak üzere uydu sistemlerinin (GNSS) modernizasyonu ve hızlı gelişimi sayesinde, konum belirleme konularında, küresel ölçekte kullanıcıya büyük kolaylıklar sağlamıştır.

Uydu sistemleri ve ölçme tekniklerindeki gelişmeler sayesinde GNSS alıcılarıyla yüksek doğrulukla konum belirlemek mümkün hale gelmiştir. Kullanılan farklı teknikler veri toplama özelliklerine göre değişmekte olup klasik anlamda mutlak ve bağıl (göreli) konum belirleme yöntemleri olarak tercih edilmektedir. Yakın zamana kadar eș zamanlı ve birden fazla alıcı kullanılarak yapılan ölçmelere alternatif yeni sistemlerin çıkmasıyla birlikte sabit alıcılara olan ihtiyaç büyük oranda ortadan kalkmıștır.

Hassas uydu yörünge bilgileri üreten bașta International GNSS Service (IGS) olmak üzere, CODE, JPL gibi kurumların kullanıcılara bu verileri sunmaları ile veri analizlerinde ve konum doğruluklarında büyük iyileşmeler yaşanmıștır. Bunlara ek olarak GNSS ölçmelerindeki hata kaynaklarının tespiti ve yeni algoritmalar ile yeni bir yaklaşım olan Hassas nokta konumlama (PPP) yöntemi geliştirilmiştir.

Hassas nokta konumlama yöntemi ile ilgili ilk çalıșmalar hassas uydu yörünge ve saat bilgileri kullanılarak başladı. Bu yörünge ve saat bilgileri ürünlerin tek GPS alıcısından alınan verilerle elde edilecek koordinatların geliștirilen algoritmalar yardımıyla iyileştirilebileceği görülmüș ve bu anlamda literatüre yeni bir teknik kazandırılmıș, birçok önemli uygulama gerçekleştirilmiştir. (Zumberge, J. F. ve ark., (1997); Kouba, J. ve Héroux, P. (2001); Gao, Y. and Shen, X. (2002); Bisnath, S. and Gao, Y. (2007); Li, X. and Zhang, $X$. (2012)). Ayrıca IGS verilerinin, PPP tekniği çözümü performansına olan etkisini incelemek için de önemli çalışmalar yapılmıştır (Kouba (2009); Weston and Schwieger, (2010)).

GNSS alıcıları ile toplanan verilerin değerlendirilmesi aşamasında kullanılan çeşitli bilimsel ve ticari veri değerlendirme yazılımları mevcuttur. Bu yazılımların kullanılması iyi bir program bilgisi, temin edilmesi için de satın alınması gerekmektedir. $\mathrm{Bu}$ bağlamda bazı araștırma merkezleri, üniversiteler, kurumlar ve firmalar web-tabanlı çevrimiçi veri değerlendirme sistemlerini geliştirmişlerdir. Bu servisler aracılı̆̆ılya tek bir GNSS alıcısı ile yapılan ölçmeler sonucu elde edilen verilerin, yöntemi mutlak (PPP) veya bağll konum çözüm yöntemi olmak suretiyle değerlendirilebilmekte ve bu servisler tamamen ücretsiz ve kullanıcılarına sinırsız kullanma imkânı sağlamaktadır.

Mutlak (PPP) ve/veya bağll yöntem çözüm teknikleri kullanılarak çevrimiçi servislerle konum belirleme ve bu servislerin performanslarının belirlenmesi ile ilgili birçok araştırma yapılmıştır.

Çevrimiçi veri değerlendirme servisleriyle yapılan ilk çalıșmalardan olan ve 24 saatlik veride tekrarlanabilir yatayda 1-2 cm, düşeyde $3-4 \mathrm{~cm}$ doğruluğa, 6 saatlik veride ise yatayda $2-4 \mathrm{~cm}$, düşeyde $3-7 \mathrm{~cm}$ ' e doğruluğa kadar erişilebildiği görülmüștür (Tsakiri, 2008).

AUSPOS, SCOUT, CSRS-PPP programları ile yapilan bir başka araștırmada çevrimiçi servislerde 24 saatlik verilerde $\mathrm{cm}$ doğruluğa erişildiği, mutlak (PPP) ve bağıl konum çözüm yöntemleri arasında çok az bir fark olduğu sonucuna varılmıștır (Cleaver, 2013).

TUSAGA-AKTiF sistemindeki 8 farklı istasyon 24 saatlik verileri ile 3 farklı bağıl çözüm yöntemi kullanan servis ve 4 farklı mutlak (PPP) çözüm yöntemi kullanan servis çözümleri kıyaslandığında, bağıl çözüm tekniği kullanan servislerden AUSPOS'un daha başarılı sonuçlar elde ettiği gözlemlenmiștir (Öcalan ve ark., 2013).

Yıldız Teknik Üniversitesi, Davutpaşa kampüsünde yapılan 3 gün, 3 saatlik iki farklı oturum verileri (birinci cihaz üstü açık bir alanda iken ikinci cihaz üstü ağaçlık bir alanda veri toplamış), mutlak (PPP) çözüm tekniği kullanan CRSS-PPP, APPS, GAPS ve bağıl çözüm tekniği kullanan OPUS, AUSPOS çevrimiçi servisleri ile değerlendirilmiş. Sonuç olarak $\mathrm{cm}$ ile $\mathrm{dm}$ mertebelerinde konumların özellikle ağaçlarla örtülü alanda mutlak çözüm yöntemiyle daha iyi performans sağladığı gözlemlenmiştir (Öcalan, T., 2016).

Yine iki farklı yaklaşımı karşıllaştıran çalışmada 24 saatlik veriler 1,2,4,6,12 saatlik alt gruplara ayrılmış sonuç olarak cm'ler mertebesinde yatay konum ve $\mathrm{dm}^{\prime}$ ler mertebesinde düșey konum için 2 saatlik verinin yeterli olduğu belirtilmiştir (Alkan ve ark., 2017).

OPUS ve AUSPOS servisleri, 24 saatlik ve 2 saatlik, 8 IGS istasyonu verileri kullanılarak yapılan noktaların gerçek kabul edilen koordinatlarına göre karşılaştırmalı bir yaklaşımla çözümlerinde, AUSPOS servisinin özellikle 2 saatlik veri çözümlerinde daha başarılı sonuçlar elde ettiği görülmüştür (Alçay ve ark., 2017).

İnternet tabanlı anllk veri değerleme yazılımlarından CSRS-PPP, AUSPOS, OPUS, APPS, GAPS, MAGIC- GNSS servisleri, Ylldız Teknik Üniversitesi YLDZ istasyonunun, 3 farklı aydaki 24 saatlik veriler temin edilmiş ve gerekli incelemeler ve analizler 5 farklı zamana göre yapılmış ve elde edilen verilere göre mutlak (PPP) çözüm yöntemi kullanan APPS programının tüm bileșenlerde daha başarll sonuçlar elde ettiği görülmüştür (Özdemir ve ark., 2019).

Yer kabuğu hareketi çalışmalarında web tabanlı çevrimiçi servislerinden CSRS-PPP, AUSPOS, OPUS veri değerlendirme servislerinin deprem anı yatay deformasyonları belirlenmesi çalışmalarında istenilen yüksek doğruluklarda koordinat elde edilebildiği saptanmıștır (Șimșek ve ark., 2019).

Bu çalışmada ise 4 farklı çevrimiçi veri değerlendirme servisinin konum doğruluğu ve sürekliliği test edilmiștir. IGS kurumunun AJAC istasyonunun 7 gün 24 saatlik RINEX (Receiver Independent Exchange) verisi $1(0-1 \mathrm{~h})$, 2(0-2h), 3(0-3h), 6(0-6h), 12(0-12h) saatlik alt gruplara ayrılmıș ve MAGIC-GNSS, CSRS-PPP, OPUS, AUSPOS veri değerlendirme servislerinde değerlendirilmiştir. Analizler sonucunda ortaya çıkan koordinat farkları ve hesaplanan standart sapmalar incelenerek mutlak (PPP) ve bağıl konum çözüm yöntemleri doğrulukları gözlemlenmiștir. 


\section{Web Tabanlı Çevrimiçi Veri Değerlendirme Servisleri}

GNSS ölçmeleri ile sahada toplanan veriler, ofiste iki farklı tür yazılımla değerlendirilir. Bunlar daha çok tektonik hareketler, deprem araștırmaları ve jeodezi amaçlı yüksek doğruluk gerektiren üniversite ve kurumlar tarafından geliştirilen bilimsel yazılımlar ve standart çözüm algoritmalarında bulunan, birçok aşaması otomatik hale getirilen ticari yazılımlardır. Bazı ticari yazılımlar modellemeler ve algoritmalarını zenginleştirerek bilimsel amaçlı değerlendirmelerde kullanılabilecek hale getirilmiştir.

İlerleyen yıllarda, programların kullanımı için yüksek GNSS bilgisine ihtiyaç, programları edinmek için ekonomik ve kullanımını öğrenmek için eğitim almak gibi unsurları geri planda bırakma adına üniversiteler, kurumlar, özel firmalar geliştirdikleri ücretsiz ve çevrimiçi GNSS veri değerlendirme servislerini kullanıcıların kullanımına açmışlardır.

Bu servislerin kullanımı, internet üzerinden kullanıcı tarafindan en basit haliyle RINEX GNSS verilerinin sisteme yüklenmesi ile başlar. Verilerin kalitesine ve süresine bağlı olarak, kullanıcılara ücretsiz çözümler üretir. Uzmanlık ve deneyimli personel ihtiyacını, bilimsel ve ticari yazılımlardaki son güncellemeleri takip etme zorunluluğunu ortadan kaldıran ve internetin olduğu her yerde erişim kolaylığı sağlaması servislerin en önemli artılarıdır.

Öbür taraftan; servislerdeki seçeneklerin sistemi kuranlar tarafından kısıtlı bırakılması, bilimsel yazılımlarda kullanılan farklı çözüm yaklaşımlarının servislerdeki eksikliği, yüksek boyutlu verilerin yüklenmesinde bazı servislerin izin vermemesi ve taşıyıcı faz başlangıç tamsayı bilinmeyeni (integer ambiguity) çözümü için yakınsama süresinin uzun olması servislerin önemli eksileridir. Santimetre mertebesinde doğruluklar için minimum 20 dakika ve daha fazla gözlem süresinin olması gerekliliği gerçek zamanlı uygulamalar açısından önemli başka bir sorundur (Rizos, 2010).

GNSS verilerinin değerlendirilmesine yönelik klasik yöntemlere alternatif olarak web tabanlı çevrimiçi servislerine ilk olarak 2001 yılında NASA Jet Propulsion Laboratory's Auto GIPSY ve Scripps Orbit ve Permanent Array Center (SOPAC) olarak hizmete girmiștir. Bu sistemlere ek olarak günümüzde Canadian Spatial Reference System Precise Point Positioning (CSRS- PPP), Australian Online Positioning Service (AUSPOS), Online Positioning User Service(OPUS), Automatic Precise Positioning Service (APPS), GPS Analysis and Positioning Software (GAPS), MAGIC-GNSS, Trimble RTX, SCOUT gibi servisler kullanıcılara ücretsiz sunulmaktadır.

$\mathrm{Bu}$ çalışmada uygulaması yapılan 4 farklı çevrimiçi veri değerlendirme servisleri ayrıntılı olarak irdelenecektir.

\subsection{MAGIC-GNSS}

MAGIC-GNSS, İspanyol GMV adındaki firmanın 2008 yılında geliștirdiği bir servistir. Kullanıcılar servise ücretsiz üye olarak RINEX verilerini sisteme yükleyebilir, statik veya kinematik mod ile çözümleme yapabilir, ayrica kullanıcıya GPS ve/veya GLONASS uydusu seçebilme seçeneği sunarak değerlendirme yapılabilir. Galileo, BeiDou ve QZSS uydu sistemleri verilerini desteklemektedir.

Sistemde değerlendirme yapabilmek için kullanılan diğer bir yöntem ise, RINEX verilerini magicppp@gmv.com mail adresine göndererek değerlendirme yaptırmaktır. Gerçek zamanlı (Real Time) PPP servisi de internetten RTCM efemeris düzeltmelerini alarak serviste kullanabilmektedir.

MAGIC-GNSS uydu yörünge ve saat senkronizasyonları, istasyon alıcı koordinat, troposferik gecikme düzeltmeleri servisin başlıca yaptığı çözümlemelerdir. Bu çözümlerde en küçük kareler algoritması programın kullandığı ana algoritmadır. ODTS (The Orbit Determination and Time Synchronization) için Dünya etrafında IGS istasyonlarından çift frekanslı kod ve taşıyıcı faz gözlemlerini işleyerek yörünge ve saat düzeltmelerini belirler (Pıriz ve ark., 2009).

Serviste çözümleme yaparken 1 saatten 24 saate kadar veri yüklemesi yapılabilmektedir. Ayrıca birden fazla verinin yörünge, saat ve koordinat analizi yapılabilir ve GMV firmasının haftalık efemeris bilgileri servisten indirilebilir. Servisin web sayfasına http://magicgnss.gmv.com (Erişim Zamanı: 9.10.2020) adresinden ulaşmak mümkündür.

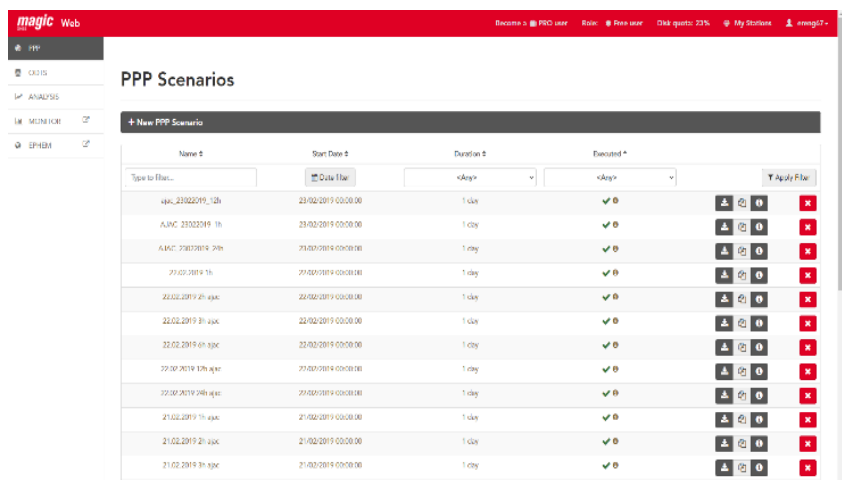

Şekil 1. MAGIC-GNSS çevrimiçi veri değerlendirme PPP çözümleme ara yüzü

Sonuçlar grafiklerle zenginleştirilmiş rapor şeklinde, istasyon saat düzeltme verileriyle beraber ETRS89 ve ITRF2014 referans sistemi koordinatlarında kullanıcıya sunulur. Servise 1'den fazla RINEX dosyası eklenebilmektedir.

\subsection{Canadian Spatial Reference System - Precise Point Positioning (CSRS- PPP)}

Geodetic Survey Division of Natural Resource Canada (NRCan) tarafindan 2003 yılında hizmete sunulan CSRSPPP servisi hassas saat ve yörünge bilgilerini kullanarak çevrimiçi veri değerlendirmesi gerçekleștirir ve ücretsiz olarak kullanıma sunulur. Statik ve Kinematik mod ile çözümleme yapılabilir, Ocean Tide loading (OTL) verisi isteğe bağlı eklenebilir.

BERNESE yazılımını kullanan CSRS-PPP servisine ASCII formatında veya .zip, .gzip, .gz, .Z, .tar, .??0 formatlarında maksimum 300 megabyte(mb) büyüklüğünde dosya yüklenebilmektedir. 


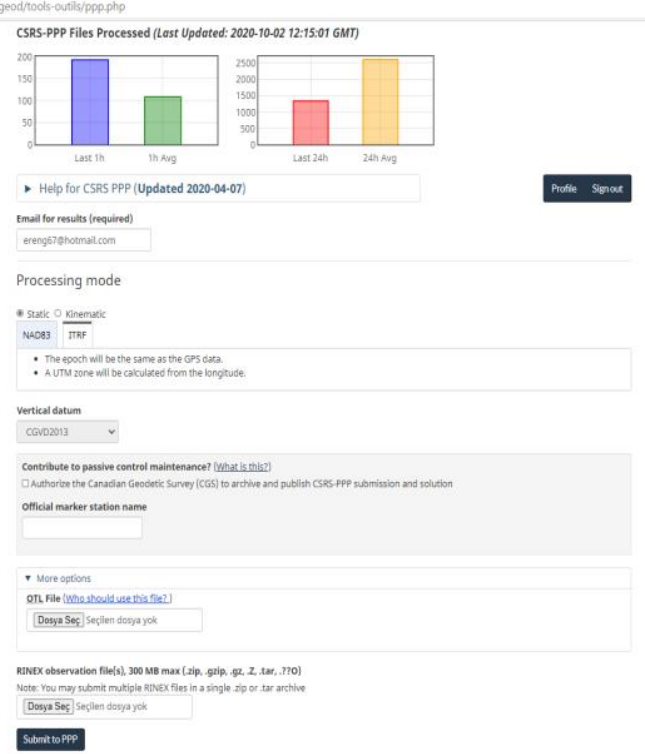

Şekil 2. CSRS-PPP çevrimiçi veri değerlendirme servisi çözümleme ara yüzü

Değerlendirme sonuçları, girilen e-mail adresine gönderilir. Sonuç dosyasında ölçüm süreleri, istasyon bilgileri, yaklaşık koordinatlar, uydu hareketleri grafikleri, troposferik gecikme grafiği, istasyon saat hataları grafiği, ambiguity grafiği ve kod, taşıyıcı faz gözlemleri grafikleri bulunur. Ayrıca .sum uzantılı dosyadan kestirilmiş kartezyen koordinatlara erişmek mümkündür. Servisin web sayfasına https://webapp.geod.nrcan.gc.ca/geod/toolsoutils/ppp.php (Erişim Zamanı: 9.10.2020) adresinden giriş yapmak mümkündür.

\subsection{Australian Online GPS Processing Service (AUSPOS)}

Avusturalya Yer bilimi (Geoscience Australia) tarafından özünde IGS istasyonlarını ve IGS ürünlerini kullanan, sadece çift frekanslı GPS faz gözlemlerini işleme esasına göre tasarlanmış, bağıl çözüm tekniğini kullanan ve 2000 yllından beri hizmet veren ücretsiz çevrimiçi veri değerlendirme servistir.

Kullanıcıya maksimum 25 tane RINEX veri yükleme imkânı veren bu servis, BERNESE v5.2 yazılımını kullanır. Gözlem verisi yüklendikten sonra en yakın 15 IGS istasyonu referans alınarak koordinat bilgileri ITRF 2014 ve Avusturalya datumu (GDA) sistemlerinde çözümlenir.

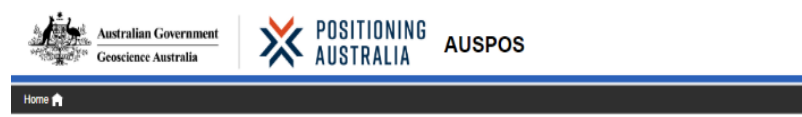

Online GPS Processing Service

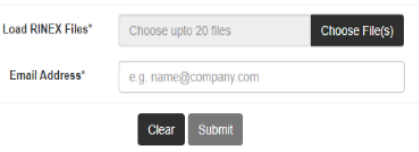

Şekil 3. AUSPOS çevrimiçi veri değerlendirme servisi çözümleme ara yüzü

Sonuç veri .pdf uzantılı dosya olarak, kullanılan IGS istasyonlarının ve yüklenen RINEX verisi kesin koordinatları, her bazın başlangıç tamsayı belirsizliği çözümü, değerlendirmelerde kullanılan gravite modeli ve konumsal doğrulukları gösteren çözümleri içeren bilgiler kullanıcıya mail gönderilir. Servisin web sayfasına https://gnss.ga.gov.au/auspos (Erişim Zamanı: 9.10.2020) adresinden erişmek mümkündür.

\subsection{Online Positioning User Service (OPUS)}

Amerikan Ulusal Okyanus ve Atmosfer İdaresinin (NOAA) kurmuş olduğu servistir. Verinin toplandığ istasyon Amerika Birleşik Devletleri dışında ise yakınındaki 3 IGS istasyonu referans olarak seçilir. Amerika Birleşik Devletleri'nde ise CORS ağındaki istasyonlar referans olarak seçilir. Servis 15 dakika ile 2 saat arasındaki gözlemleri hızlı statik yönteme göre çözüm yaparken RSGPS yazılımı kullanır. 2 saat ile 48 saat arasındaki gözlemleri statik yönteme göre çözüm yaparken Program for Adjustment of GPS Ephemerides (PAGES) yazılımı kullanır (URL-1).

Ücretsiz olarak kullanıcılara açık olan programa veri yüklerken RINEX2, RINEX3, .zip, gzip ve hatanaka formatlarından biri olması yeterlidir. Veri yükleme dışında anten yüksekliği, anten tipi ve e-mail adresi girilmelidir. Anten bilgilerindeki hatalı girişler sonuç data analizlerinde anten problemi diye kullanıcı bilgilendirilir.

Kullanıcı mail adresine gelen sonuçta, kullanılan referans istasyonları bilgileri, navigasyon ve efemeris dosyaları adları, ölçüm aralığı, anten tipi, anten yüksekliği, kullanılan yazılım ve ITRF 2014 datumundaki koordinat değerleri bulunmaktadır.
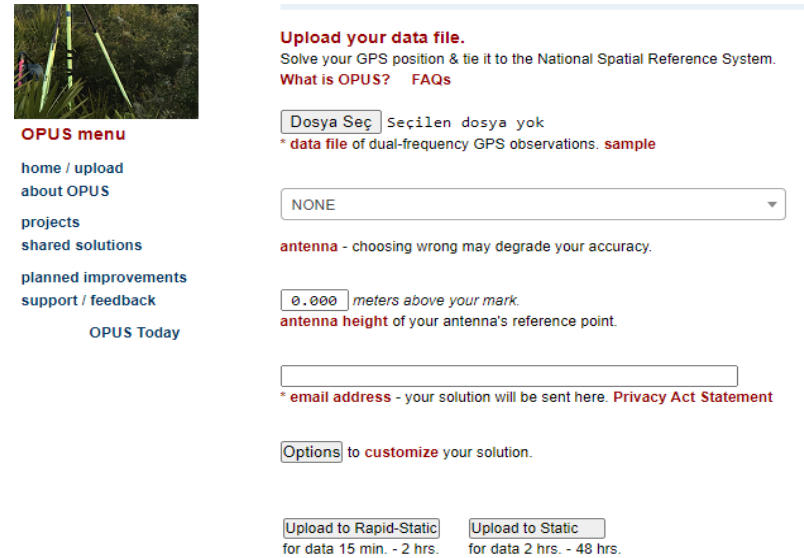

Şekil 4. OPUS çevrimiçi veri değerlendirme servisi çözümleme ara yüzü

Ayrıca Amerika Birleşik Devletleri kullanıcıları için istenilen CORS istasyonunu ekleme veya çıkarma özelliği, çalışılan eyalet seçimi, verilerin diğer kullanıcılar ile paylaşılması gibi seçenekler mevcuttur. Servisin web sayfasına https://www.ngs.noaa.gov/OPUS/ (Erişim Zamanı: 9.10.2020) adresinden erişmek mümkündür. 
Tablo 1. Web-Tabanlı Çevrimiçi Veri Değerlendirme Servisleri ve Özellikleri

\begin{tabular}{|c|c|c|c|c|}
\hline Özellikler & $\begin{array}{l}\text { MAGIC- } \\
\text { GNSS }\end{array}$ & CSRS-PPP & AUSPOS & OPUS \\
\hline $\begin{array}{l}\text { Çözüm } \\
\text { Yöntemi }\end{array}$ & Mutlak & Mutlak & Bağıl & Bağıl \\
\hline $\begin{array}{c}\text { Referans } \\
\text { Yüzeyi }\end{array}$ & ITRF14 & ITRF14 & ITRF14 & ITRF14 \\
\hline $\begin{array}{l}\text { Kullanilan } \\
\text { Yazılım }\end{array}$ & $\begin{array}{l}\text { MAGIC- } \\
\text { GNSS }\end{array}$ & BERNESE & $\begin{array}{c}\text { BERNE } \\
\text { SE }\end{array}$ & PAGES \\
\hline $\begin{array}{c}\text { Desteklediğ } \\
\text { i Uydular }\end{array}$ & $\begin{array}{c}\text { GPS } \\
\text { GLONASS } \\
\text { GALILEO } \\
\text { BEIDOU } \\
\text { QZSS }\end{array}$ & $\begin{array}{c}\text { GPS } \\
\text { GLONASS }\end{array}$ & GPS & GPS \\
\hline $\begin{array}{l}\text { Geliștiren } \\
\text { Kurum }\end{array}$ & $\begin{array}{c}\text { GMV } \\
\text { Innavation } \\
\text { Solutions }\end{array}$ & $\begin{array}{l}\text { Natural } \\
\text { Resources } \\
\text { Canada }\end{array}$ & $\begin{array}{c}\text { Geoscie } \\
\text { nce } \\
\text { Australi } \\
\text { a }\end{array}$ & $\begin{array}{c}\text { National } \\
\text { Geodetic } \\
\text { Survey }\end{array}$ \\
\hline $\begin{array}{c}\text { Uydu } \\
\text { Yükseklik } \\
\text { Açısı }\end{array}$ & 10 derece & 7,5 derece & $\begin{array}{c}7 \\
\text { derece }\end{array}$ & 10 derece \\
\hline $\begin{array}{c}\text { Uydu } \\
\text { Yörünge, } \\
\text { Saat Bilgisi } \\
\text { ve Anten } \\
\text { Düzeltmesi }\end{array}$ & IGS & IGS & IGS & IGS \\
\hline $\begin{array}{l}\text { Troposfer } \\
\text { Modeli }\end{array}$ & GMF & GMF & GMF & GMF \\
\hline Veri & 1,2,5,10, & 1,2,5,10, & 30 & 30 \\
\hline $\begin{array}{l}\text { Toplama } \\
\text { Aralığı }\end{array}$ & $\begin{array}{c}\text { 15,30,60, } \\
300 \text { saniye } \\
\text { olabilir }\end{array}$ & $\begin{array}{c}\text { 15,30,60, } \\
300 \text { saniye } \\
\text { olabilir }\end{array}$ & $\begin{array}{c}\text { saniyey } \\
\mathrm{e} \\
\text { indirger }\end{array}$ & $\begin{array}{l}\text { saniyeye } \\
\text { indirger }\end{array}$ \\
\hline Üyelik & $\begin{array}{c}\text { Var } \\
\text { Ücretsiz }\end{array}$ & $\begin{array}{c}\text { Var } \\
\text { Ücretsiz }\end{array}$ & $\begin{array}{c}\text { Yok } \\
\text { Ücretsiz }\end{array}$ & $\begin{array}{c}\text { Yok } \\
\text { Ücretsiz }\end{array}$ \\
\hline $\begin{array}{l}\text { Gözlem } \\
\text { Verisi }\end{array}$ & $\begin{array}{c}\text { Çift } \\
\text { Frekans, } \\
\text { Statik veya } \\
\text { Kinematik }\end{array}$ & $\begin{array}{l}\text { Tek ve Çift } \\
\text { Frekans, } \\
\text { Statik veya } \\
\text { Kinematik }\end{array}$ & $\begin{array}{c}\text { Çift } \\
\text { Frekans } \\
\text {, Statik }\end{array}$ & $\begin{array}{l}\text { Çift } \\
\text { Frekans, } \\
\text { Statik }\end{array}$ \\
\hline $\begin{array}{c}\text { Data } \\
\text { Formatı }\end{array}$ & $\begin{array}{c}\text { RINEX } \\
\text {.Z } \\
\text {.gz } \\
\text {.zip }\end{array}$ & $\begin{array}{c}\text { RINEX } \\
. \mathrm{Z} \\
\text {.gz } \\
\text {.gzip } \\
\text {.tar } \\
. ? ? 0\end{array}$ & $\begin{array}{c}\text { RINEX } \\
\text {.zip } \\
\text {.gz } \\
. \mathrm{bz} \\
\text { Hatana } \\
\text { ka } \\
\text { formatı }\end{array}$ & $\begin{array}{l}\text { RINEX } \\
\text { UNIX, } \\
\text { gzip, } \\
\text { pkzip, } \\
\text { Hatanaka } \\
\text { formatı }\end{array}$ \\
\hline Kısitlama & $\begin{array}{l}\text { Ücretsiz } \\
\text { çözümleme } \\
\text { lerde } \\
\text { RINEX veri } \\
\text { kotası var. } \\
\text { (\%100 } \\
\text { max) }\end{array}$ & $\begin{array}{l}\text { Maksimum } \\
300 \mathrm{mb} \\
\text { dosya } \\
\text { yüklemeye } \\
\text { izin verir. }\end{array}$ & $\begin{array}{c}\text { Maksim } \\
\text { um } 25 \\
\text { RINEX } \\
\text { verisi } \\
\text { yüklene } \\
\text { bilir. }\end{array}$ & $\begin{array}{c}2 \text { saat altı } \\
\text { veri statik } \\
\text { çözüm } \\
\text { olmaz } \\
\text { (hızlı } \\
\text { statik) }\end{array}$ \\
\hline $\begin{array}{c}\text { Web } \\
\text { Sayfası }\end{array}$ & $\begin{array}{l}\text { http://ma } \\
\text { gicgnss.g } \\
\text { mv.com }\end{array}$ & $\begin{array}{c}\text { https://w } \\
\text { ebapp.geo } \\
\text { d.nrcan.gc. } \\
\text { ca/geod/t } \\
\text { ools- } \\
\text { outils/ppp } \\
\text {.php }\end{array}$ & $\begin{array}{l}\text { https:/ } \\
\text { /gnss.g } \\
\text { a.gov.a } \\
\text { u/ausp } \\
\text { os }\end{array}$ & $\begin{array}{c}\text { https:// } \\
\text { www.ng } \\
\text { s.noaa.g } \\
\text { ov/OPU } \\
\text { S/ }\end{array}$ \\
\hline
\end{tabular}

\section{UYGULAMA}

Bu çalışma için Akdeniz'de Fransa'ya bağlı bir ada olan Korsika'daki Ajaccio kentindeki IGS istasyonu
(AJAC) seçilmiştir. Seçilen istasyonun konumu Şekil 5’ de detaylar ise Tablo 2'de verilmiştir.

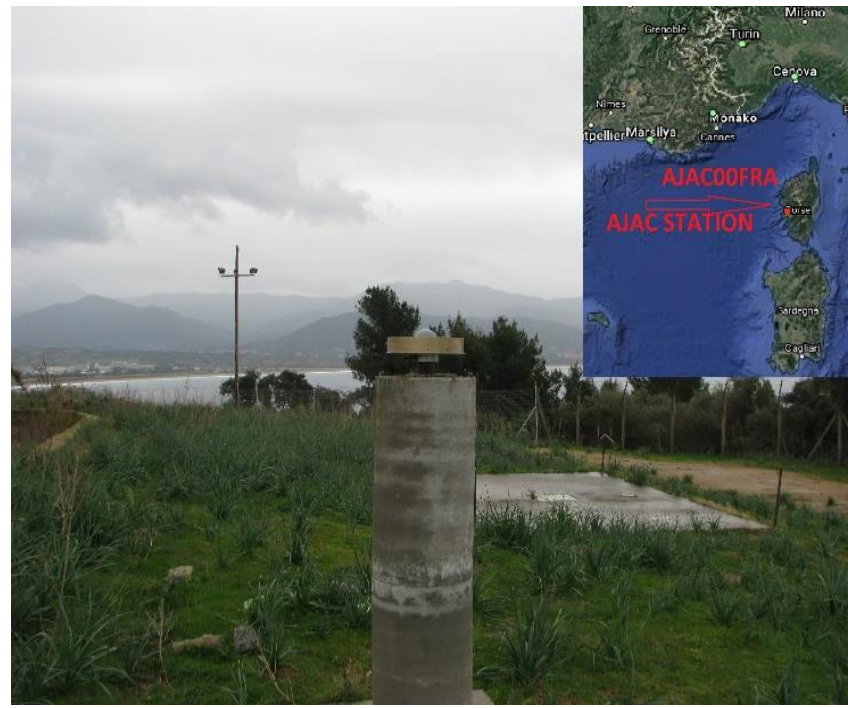

Şekil 5. IGS AJAC istasyonu görseli ve uydu görünümü

Tablo 2. Test edilen IGS istasyonu detayları (URL-2)

\begin{tabular}{ll}
\hline & \multicolumn{1}{c}{ IGS AJAC İstasyonu } \\
\hline Site ID & AJAC00FRA \\
Ülke & Fransa \\
Anten & TR57971_NONE (2018-09-2019-03) \\
Alıcl & LEICA GR25 (2018-09 - 2019-03) \\
Uydular & GPS, GLONASS, Galileo, BeiDou, SBAS \\
X kartezyen & 4696989.24012146 (ITRF 2014) \\
Y kartezyen & 723994.74594873 (ITRF2014) \\
Z kartezyen & 4239678.70982776(ITRF 2014) \\
\hline
\end{tabular}

Calıșmada kullanılan 17.02.2019'dan 23.02.2019 (DOY048-DOY054) tarihine kadar olan, zamana bağlı doğrulukları inceleme ve sürekliliğin sağlanabilirliğini gözlemlemek adına 1 haftalık gözlem verisi 24 saatlik veriler halinde temin edilmiştir.

24 saatlik veriler, kısa gözlem sürelerinin sonuçlar üzerindeki etkisini gözlemlemek adına $1(0-1 \mathrm{~h}), 2(0-2 \mathrm{~h})$, $3(0-3 \mathrm{~h}), 6(0-6 \mathrm{~h}), 12(0-12 \mathrm{~h})$ saatlik alt oturumlar halinde hazırlanarak mutlak (PPP) tekniğiyle çözüm yapan MAGIC-GNSS, CSRS-PPP servislerinde, bağıl çözüm tekniği kullanan AUSPOS, OPUS servislerinde olmak üzere toplam 159 adet veri değerlendirmesi (OPUS servisi 1 saatlik veriler değerlendirilmemiştir) yapılmıştır.

Çevrimiçi veri değerlendirme servislerinden elde edilen tüm kartezyen koordinatlar, AJAC istasyonu Kartezyen kesin koordinatlarıyla (ITRF 2014) karşılaştırılmıştır. İkinci olarak haftalık veri seti her servis için ortalama değerleri alınarak, AJAC istasyonu kesin koordinat değerleri ile kıyaslanmıştır. Son olarak standart sapmaları her servis için her saat veri setine göre hesaplanmış ve sonuçlar irdelenmiştir.

\section{BULGULAR}

Değerlendirme sonuçlarına göre tüm servislerin $X$ bileşenleri koordinatları, kesin istasyon koordinatına göre farkları Şekil 6'daki gibidir. 

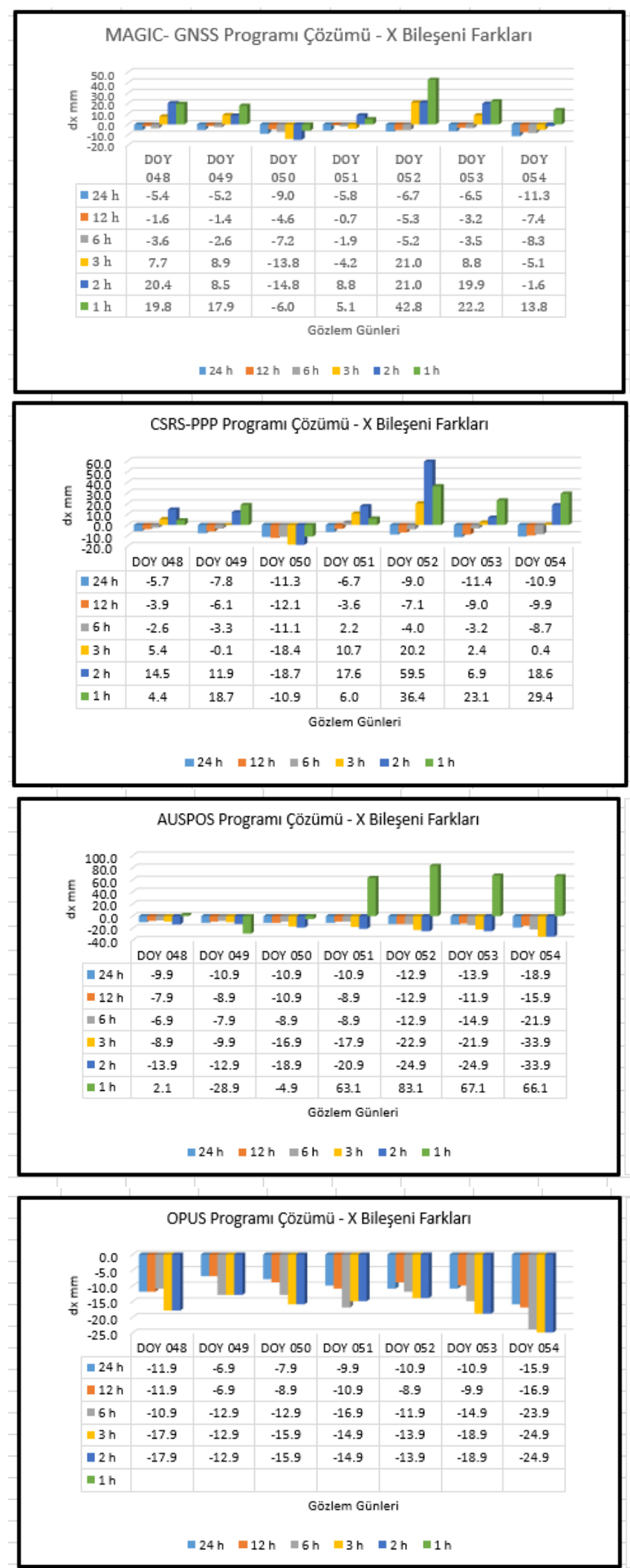

Şekil 6. Tüm Servislerin AJAC istasyonu kesin koordinatlara kıyas ederek tüm saat dilimlerindeki $\mathrm{X}$ bileşeni kartezyen koordinat farkları (mm)

Değerlendirme sonuçlarına göre MAGIC-GNSS servisi ile $X$ bileșeninde 6 saat ve sonrasında mm ve \pm 1 cm doğruluğu, 2 ve 3 saatlik oturumlarda mm ve $\pm 1-2 \mathrm{~cm}$, CSRS-PPP servisi aynı şekilde 6 saat ve sonrasında $\mathrm{mm}$ ve $\pm 1 \mathrm{~cm}$ düzeylerinde, 2 ve 3 saatlik oturumlarda $\mathrm{mm}$ ve $\pm 1-2$ cm konum doğruluğu elde edilirken, bazı günlerdeki veri servisleri değerlendirmelerinde kimi bileșenlerde 1 saatlik veri koordinat çözümlerinin 24 saatlik veriye göre kesin istasyon koordinatlarına göre daha yakın olduğunun görülmesi bazı mantıksal çelișkilere neden olmuștur. Şekil 7'de görüldüğü üzere, CSRS- PPP servisi 1 saatlik veri ile 24 saatlik veri çözümü karşılaştırıldığında, 1 saatlik verideki birim koordinat hataları (tekrarlanabilirlik) 4-8 cm mertebesindeyken 24 saatlik veri çözümünde birim koordinat hataları aralığı $\mathrm{mm}-1 \mathrm{~cm}$ aralığında olduğu ve 1 saatlik verilerin konum doğruluklarının tekrarlanabilir olmadığı, diğer servislerde de çözümler karşılaştırıldığında benzer durumların yaşandığı gözlemlenmiştir.

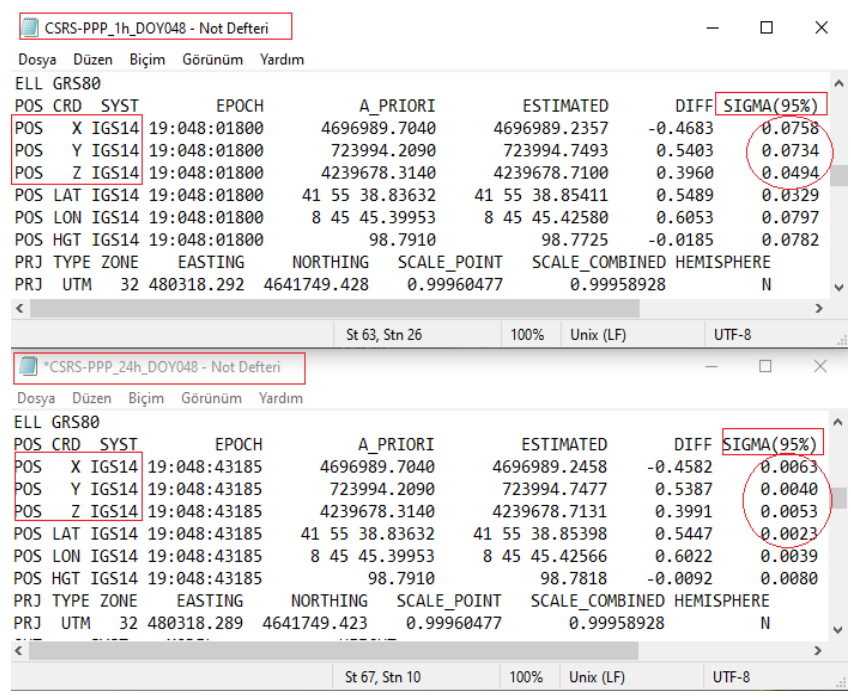

Şekil 7. CSRS-PPP Servisi 1 saat ve 24 saatlik (DOY048) veri çözüm dosyaları karşılaştırılması

AUSPOS servisi 2 saat üstü verilerde $\pm 1-3 \mathrm{~cm}$ düzeylerinde doğruluk elde ettiği gözlemlenmiştir. 1 saatlik gözlemlerde bazı günlerde $\mathrm{mm}$ seviyelerinde gözükmesi üzerine günlük veri çözümü incelemesinde standart sapmanın dm seviyesinde olduğu görülmüştür. AUSPOS servisi en yakın 15 IGS noktasından yararlanarak baz çözümü ile noktaların koordinatları kestirir her oturum çözümlemesinde farklı istasyon verilerinden faydalandığı ve baz vektörlerinin konum doğruluğuna etki ettiği görülmüștür. 6 saat ve üstü veri çözümlerinde daha başarılı ve benzer sonuçlar elde ettiği söylenebilir. OPUS servisi çözümleri incelendiğinde genel itibariyle mm ve $\pm 1-3 \mathrm{~cm}$ düzeylerinde olduğu, 6 saat üstü çözümlerde $\mathrm{mm}$ ve $\pm 1-2 \mathrm{~cm}$ seviyelerinde olduğu, değișkenliğin az olmasında farklı saat çözümlerinde OPUS servisinin yakınındaki benzer 3 IGS servisinin seçiminin etkili olduğu gözlemlenmiştir. Ayrıca uzun gözlemlerde, multipath hatalarını gidermede ve taşıyıcı faz belirsizliği(ambiguity) çözümlerinde başarılı sonuçlar verdiği yapılan çalışma ile değinilmiştir (Gillins ve ark. 2019).

Değerlendirme sonuçlarına göre tüm servislerin $\mathrm{Y}$ bileșenleri koordinatları, kesin istasyon koordinatına göre farkları Şekil 8'daki gibidir.

Değerlendirme sonuçları MAGIC-GNSS servisi 3 saat ve üstü çözümlerde $\mathrm{mm}$ konum doğruluğunda gözlemlenirken diğer saat çözümlerinde $\mathrm{cm}$ düzeylerinde olduğu, gün bazlı incelendiğinde DOY052 gözlem günündeki, iyonosferik etkilerin ve manyetik fırtınaların etkisini en aza indirmek için Kp-indeks 
değerleri incelendiğinde, atmosferik etkiler mutlak çözüm yaklaşımı sunan servislerde Şekil 9'daki gibi etki ettiği görülmüștür. Özellikle ilk 3 saat veri çözümlerinde Kp-indeksinin etkileri görülmektedir.
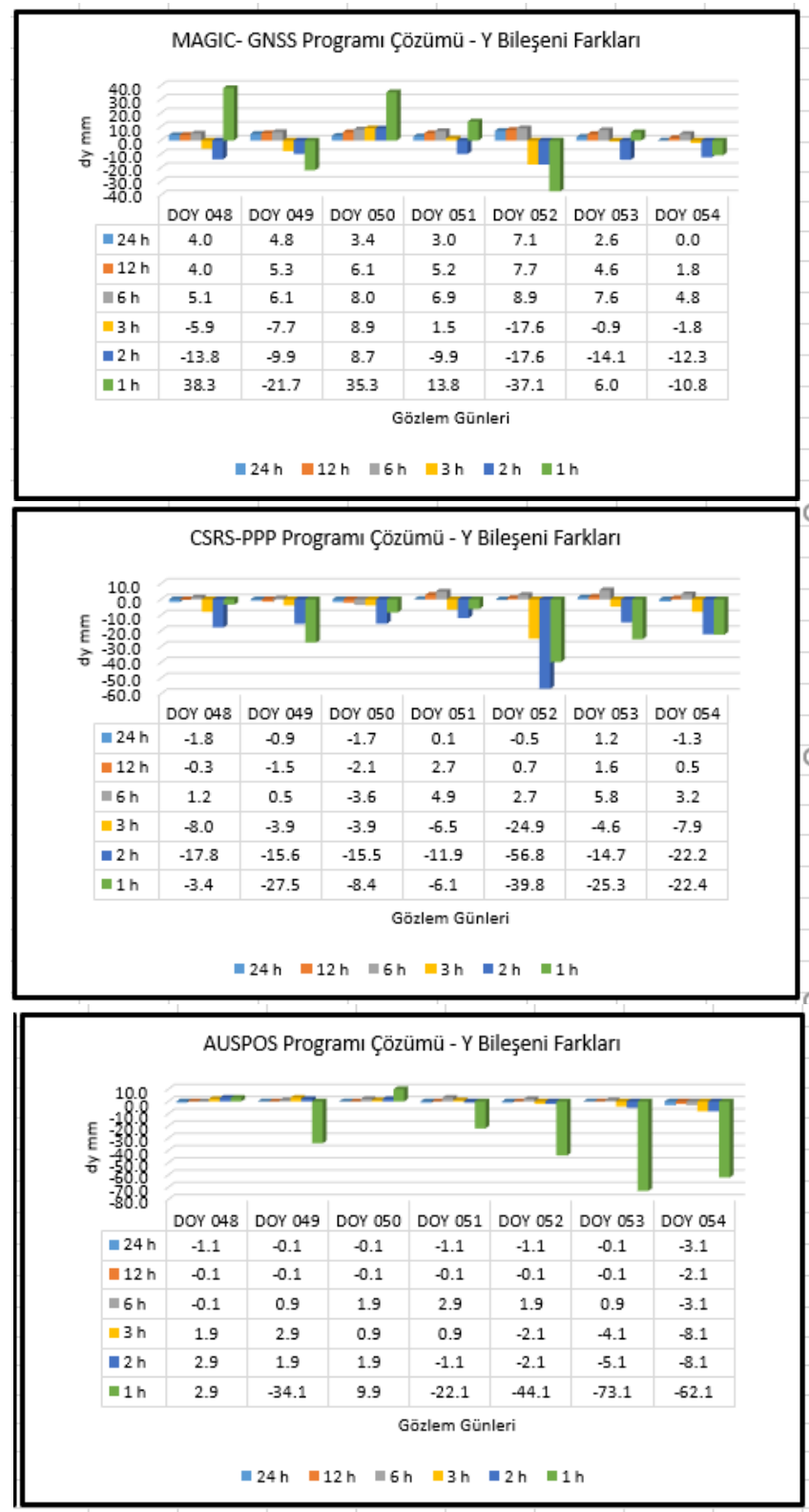

OPUS Programı Çözümü - Y Bileşeni Farkları

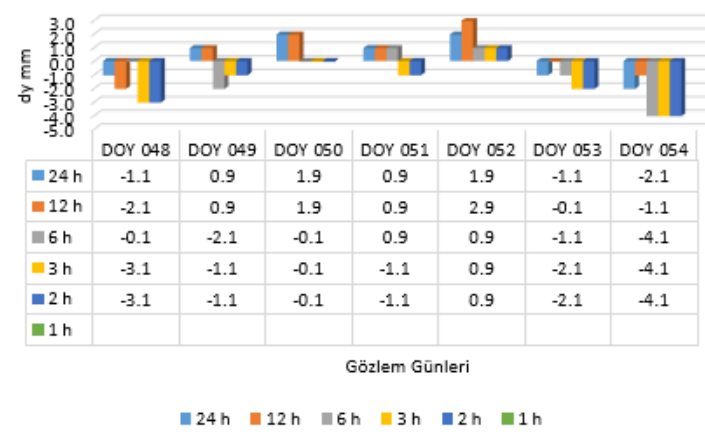

Şekil 8. Tüm servislerin AJAC istasyonu kesin koordinatlarına göre tüm saat dilimlerindeki Y bileşeni kartezyen koordinat farkları (mm)

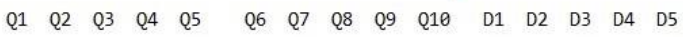

\begin{tabular}{|c|c|c|c|c|c|c|c|c|c|c|c|c|c|c|c|c|}
\hline an & 2019 & 2 & 28 & 3 & 30 & 12 & 13 & 29 & 10 & 21 & 20 & $24 *$ & $5 *$ & $23^{*}$ & & $25 *$ \\
\hline Feb & 2019 & 25 & 24 & 23 & 26 & 19 & 20 & 22 & 16 & 15 & 17 & 28 & $2^{*}$ & $1^{*}$ & $13^{*}$ & $21^{*}$ \\
\hline & 2019 & 22 & 23 & 21 & 18 & 11 & 4 & 30 & 13 & 10 & 5 & 1 & $17 *$ & $2^{*}$ & $16 *$ & $28^{*}$ \\
\hline & 2019 & 18 & 22 & 21 & 17 & 2 & 26 & 14 & 19 & 30 & 28 & $10 *$ & $5 *$ & 8* & $3 *$ & $4 *$ \\
\hline May & 2019 & 8 & 19 & 5 & 21 & 25 & 31 & 22 & 12 & 18 & 17 & 14 & 11 & $29 *$ & $1^{*}$ & $2 * \mid$ \\
\hline & 2019 & 11 & 6 & 10 & 17 & & & 29 & 19 & 8 & 12 & 8 & $13^{*}$ & $4^{*}$ & $20^{*}$ & $14^{*}$ \\
\hline & & 26 & 20 & 25 & 6 & & & 3 & 5 & 24 & 7 & $9 *$ & $10 *$ & $30 *$ & 1* & 8* \\
\hline Aug & 2019 & 3 & 19 & 2 & 29 & 15 & 4 & 25 & 14 & 23 & 21 & 31 & 5 & $27^{*}$ & $6^{*}$ & $30^{*}$ \\
\hline & 2019 & 20 & 23 & 19 & 26 & 2 & & 11 & 10 & 12 & 14 & 1 & 28 & 2 & 27 & 9* \\
\hline & 2019 & 13 & 23 & 22 & 3 & 19 & 15 & 8 & 6 & 20 & 17 & 25 & 26 & $24 *$ & $27^{*}$ & $10 *$ \\
\hline & 019 & 18 & 2 & 3 & 20 & 13 & 15 & 19 & 8 & 10 & 14 & $22^{*}$ & $24 *$ & $21 *$ & $23^{*}$ & $11^{*}$ \\
\hline & 2019 & 3 & 29 & 28 & 30 & & 2 & 7 & 17 & 16 & 24 & $18^{*}$ & $19 *$ & $11 *$ & $20 *$ & $15 *$ \\
\hline
\end{tabular}

Şekil 9. 2019 yılı aylara göre Kp- indeks değerlerinin düşük ve yüksek olduğu günler (DOY052 (21 Şubat)) (URL - 3)

CSRS-PPP servisleri ile $Y$ bileşeninde 3 saat ve üstünde mm konum doğruluğu elde edilirken, 3 saat altı cm'ler düzeylerinde seyrettiği görülürken, AUSPOS ve OPUS programı daha iyi performans gösterip 2 saat ve üstünde $\mathrm{mm}$ konum doğruluğu elde ettiği gözlemlenmiştir. Özellikle Bağıl konum çözüm tekniği kullanan servislerin Y bileşeni çözümlerinde, kullandıkları IGS istasyonları baz hatları ve taşıyıcı faz belirsizliği çözümlerinin doğruluk yüzdeleri, konumu iyileştirdiği ve başarılı sonuçlar elde ettikleri görülmektedir.

Değerlendirme sonuçlarına göre tüm servislerin $\mathrm{Z}$ bileşeni kartezyen koordinatları, kesin istasyon koordinatına göre farkları Şekil 10'deki gibidir.

Değerlendirme sonuçlarına göre MAGIC-GNSS servisi $\mathrm{Z}$ bileșeninde 2 saat ve sonrasında $\mathrm{mm}- \pm 1 \mathrm{~cm}$ doğruluğunda olduğu, CSRS-PPP servisi genel olarak $\mathrm{mm}- \pm 2 \mathrm{~cm}$ düzeyinde konum doğruluğu elde edilmiștir. Çoklu GNSS çözümlerinde enlem ve gözlem süresinin konum doğruluğuna etkisi ile ilgili yapılan çalışmada (Sezer ve ark., 2021) sadece gözlem süresinin etkili olduğu, enlemin herhangi bir anlamlı etkisinin olmadığı gözlemlenmiștir. MAGIC- GNSS servisinin Z bileşenindeki başarısının, geliştirilmiş hassas nokta konumlama (PPP) çözüm algoritmaları ve hata kaynakları çözüm modellerinin daha bașarılı olduğu sonucunu çıkartmaktadır. AUSPOS servisinde 3 saat sonrasında $\mathrm{mm}$ 'den \pm 2 cm'ye kadar, 1 ve 2 saat gözlemlerinde ise $\pm 1-4 \mathrm{~cm}$ düzeylerinde olduğu görülmektedir. OPUS servisinde genel olarak $\pm 1-2 \mathrm{~cm}$ doğruluk düzeyinde sonuçlar elde edildiği gözlemlenmiștir. Genel olarak 6 saat ve üstü veri çözümlerinde $\mathrm{Z}$ bileșeni için özellikle mutlak (PPP) yöntemi ile çözüm yapan servislerin mm konum doğrulukta başarılı sonuçlar elde edildiği görülmektedir. Bağıl çözüm yöntemi kullanan her iki servis ile de 12 saat ve üstü veri çözümlerinde $\mathrm{mm}- \pm 2 \mathrm{~cm}$ düzeyinde sonuçlar elde ettiği görülmektedir.

İkinci uygulamada, 6 farklı saat aralığındaki haftalık veri setlerinin ortalama değerleri alınarak, AJAC istasyonu kesin koordinat değerinden farkları alınmıș ve görülmüştür ki, tüm servislerde özellikle 24, 12, 6 saat dilimlerinde farkların maksimum $\pm 1.1 \mathrm{~cm}$ doğruluğunda seyrettiği ve ortalama değerlerin kesin koordinat değerlerine yakınlığı, servislerdeki çözümlerin tekrarlanabilir olduğunu göstermiştir. 

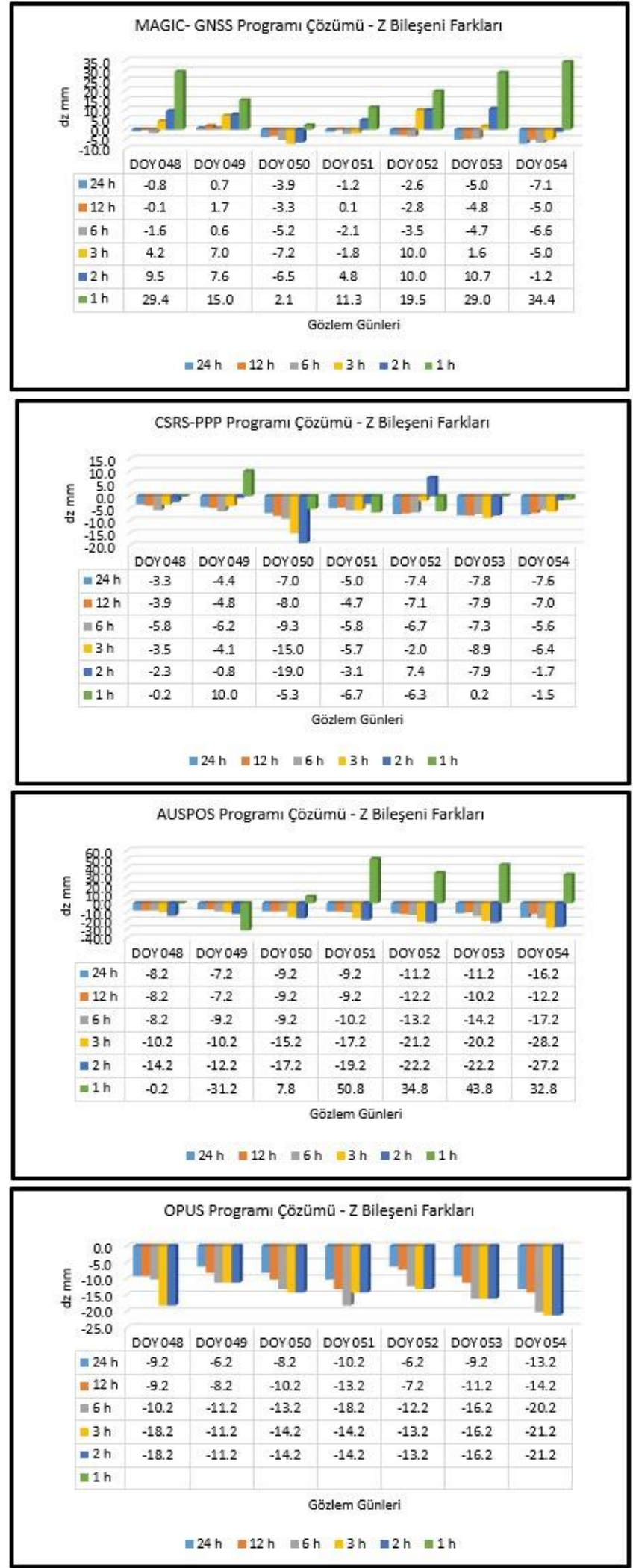

Şekil 10. Tüm servislerin AJAC istasyonu kesin koordinatlarına göre tüm saat dilimlerindeki $\mathrm{Z}$ bileșeni kartezyen koordinat farkları (mm)

1 ile 3 saat aralığında ise MAGIC-GNSS ve CSRS-PPP servisleri maksimum 2 cm'ye kadar doğruluk elde ederken AUSPOS servisi $\pm 1-4 \mathrm{~cm}$ aralığında, OPUS servisi ile $\pm 2 \mathrm{~cm}$ doğruluğunda elde edilmiștir.

Dikkat çeken diğer bir sonuç, MAGIC-GNSS ve CSRSPPP servislerinde 3 saat ve üstü gözlem aralıklarında tüm bileşenlerdeki doğruluğun $\mathrm{mm}$ düzeyinde olmasıdır. Ayrıntılı değerler ve grafik Şekil 12'deki gibidir.

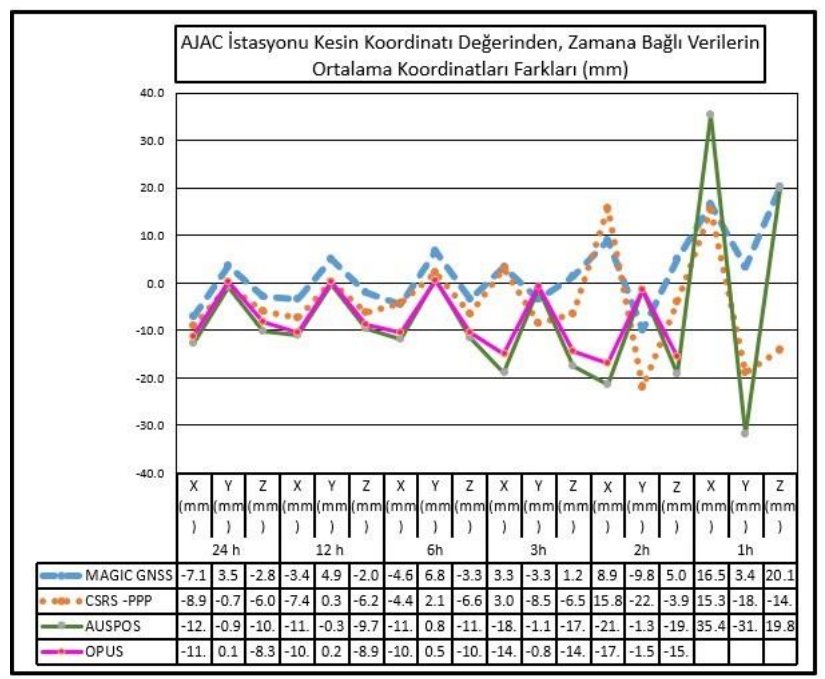

Şekil 11. Tüm servislerdeki farklı zaman oturumlarındaki verilerin ortalamalarının AJAC istasyonu kesin koordinatlarına olan farkları ( $\mathrm{mm}$ )

Sonuç verilerinin tekrar edilebilir olduğunu ve servislerin iyi bir değerlendirme yaptığını belirleyebilmek için 7 günlük veri çözümlerinin her saat dilimlerine göre koordinat değerlerinin standart sapmaları hesaplanmıștır.

MAGIC-GNSS servisi tüm bileșenlerinde standart sapma değerleri 1 saate kadar $\mathrm{mm}-1 \mathrm{~cm}$ aralığında iken CSRS-PPP servisi standart sapması 3 saat altındaki analizlerde $1-2 \mathrm{~cm}$ aralığında olduğu, AUSPOS servisinde 1 saatlik gözlemlerdeki $2-4$ cm'lik sapmalar görülmesine karşın diğer saat dilimlerinde mm'lerde olduğu, bunda da etkili olan husus 1 saatlik çözüm dosyasındaki baz vektörlerindeki ambiguity çözümlerinin etki ettiği, OPUS servisinde de tüm saat aralıklarında $\mathrm{mm}$ düzeylerinde sonuçlar elde edildiği görülmektedir. OPUS servisinin farklı oturumlardaki veri çözümleri konum doğruluklarında da görüldüğü üzere servisin kendisine en yakın benzer 3 IGS istasyonu seçimi standart sapmalardaki benzer sonuçları elde edildiğini göstermektedir.

Tüm servislerin tüm saat dilimlerindeki 7 günlük koordinat verileri ortalama değerlerine göre olan standart sapma değerlerini Tablo 3'den ve grafik gösterimlerini ise Şekil 12'den ayrıntılı olarak incelemek mümkündür.

Tablo 3. Tüm servislerin zamana göre standart sapmaları (mm)

\begin{tabular}{|c|c|c|c|c|c|c|c|}
\hline \multicolumn{4}{|c|}{ MAGIC-GNSS Servisi Standart Sapmaları ( $\mathrm{mm}$} & \multicolumn{4}{|c|}{ CSRS-PPP Servisi Standart Sapmaları (mm) } \\
\hline & $\mathrm{dx}$ & dy & $\mathrm{dz}$ & & $\mathrm{dx}$ & dy & $\mathrm{dz}$ \\
\hline $24 \mathrm{~h} \mathrm{std}(\mathrm{mm})$ & 2.2 & 2.2 & 2.6 & $24 \mathrm{~h} \mathrm{std}(\mathrm{mm})$ & 2.3 & 1.1 & 1.4 \\
\hline $12 \mathrm{~h} \mathrm{std}(\mathrm{mm})$ & 2.4 & 1.8 & 2.6 & $12 \mathrm{~h} \mathrm{std}(\mathrm{mm})$ & 3.1 & 1.7 & 1.7 \\
\hline $6 \mathrm{~h} \mathrm{std}(\mathrm{mm})$ & 2.4 & 1.5 & 2.5 & $6 \mathrm{~h} \mathrm{std}(\mathrm{mm})$ & 4.3 & 3.1 & 1.3 \\
\hline $3 \mathrm{~h} \mathrm{std}(\mathrm{mm})$ & 11.7 & 8.3 & 5.3 & $3 \mathrm{~h} \mathrm{std}(\mathrm{mm})$ & 11.8 & 7.4 & 4.4 \\
\hline $2 \mathrm{~h} \mathrm{std}(\mathrm{n}$ & 13. & 8.6 & & $2 \mathrm{~h} \mathrm{std}$ & 23.1 & 15.6 & 8.1 \\
\hline $1 \mathrm{~h} \mathrm{std}(\mathrm{mm})$ & 15.2 & 28.3 & 11.5 & $1 \mathrm{~h} \mathrm{std}(\mathrm{mm})$ & 16.4 & 13.4 & 5.8 \\
\hline
\end{tabular}

\begin{tabular}{|c|c|c|c|c|c|c|c|}
\hline \multicolumn{4}{|c|}{ AUSPOS Servisi Standart Sapmaları (mm) } & \multicolumn{4}{|c|}{ OPUS Servisi Standart Sapmaları (mm) } \\
\hline & $\mathrm{dx}$ & dy & $\mathrm{dz}$ & & $\mathrm{dx}$ & dy & $\mathrm{dz}$ \\
\hline $24 \mathrm{~h} \mathrm{std}(\mathrm{mm})$ & 3.1 & 1.1 & 2.8 & $24 \mathrm{~h} \mathrm{std}(\mathrm{mm})$ & 4.2 & 1.3 & 2.5 \\
\hline $12 \mathrm{~h} \mathrm{std}(\mathrm{mm})$ & 2.8 & 0.8 & 1.9 & $12 \mathrm{~h} \mathrm{std}(\mathrm{mm})$ & 2.9 & 1.6 & 2.4 \\
\hline $6 \mathrm{~h} \mathrm{std}(\mathrm{mm})$ & 5.3 & 2.0 & 3.3 & $6 \mathrm{~h} \mathrm{std}(\mathrm{mm})$ & 3.2 & 1.7 & 2.6 \\
\hline $3 \mathrm{~h} \mathrm{std}(\mathrm{mm})$ & 8.5 & 3.9 & 6.4 & $3 \mathrm{~h} \mathrm{std}(\mathrm{mm})$ & 4.4 & 1.8 & 3.8 \\
\hline $2 \mathrm{~h} \mathrm{std}(\mathrm{mm})$ & 7.3 & 4.1 & 5.2 & $2 \mathrm{~h} \mathrm{std}(\mathrm{mm})$ & 4.1 & 1.7 & 3.4 \\
\hline $1 \mathrm{~h} \mathrm{std}(\mathrm{mm})$ & 44.5 & 31.1 & 29.1 & $1 \mathrm{~h} \mathrm{std}(\mathrm{mm})$ & & & \\
\hline
\end{tabular}



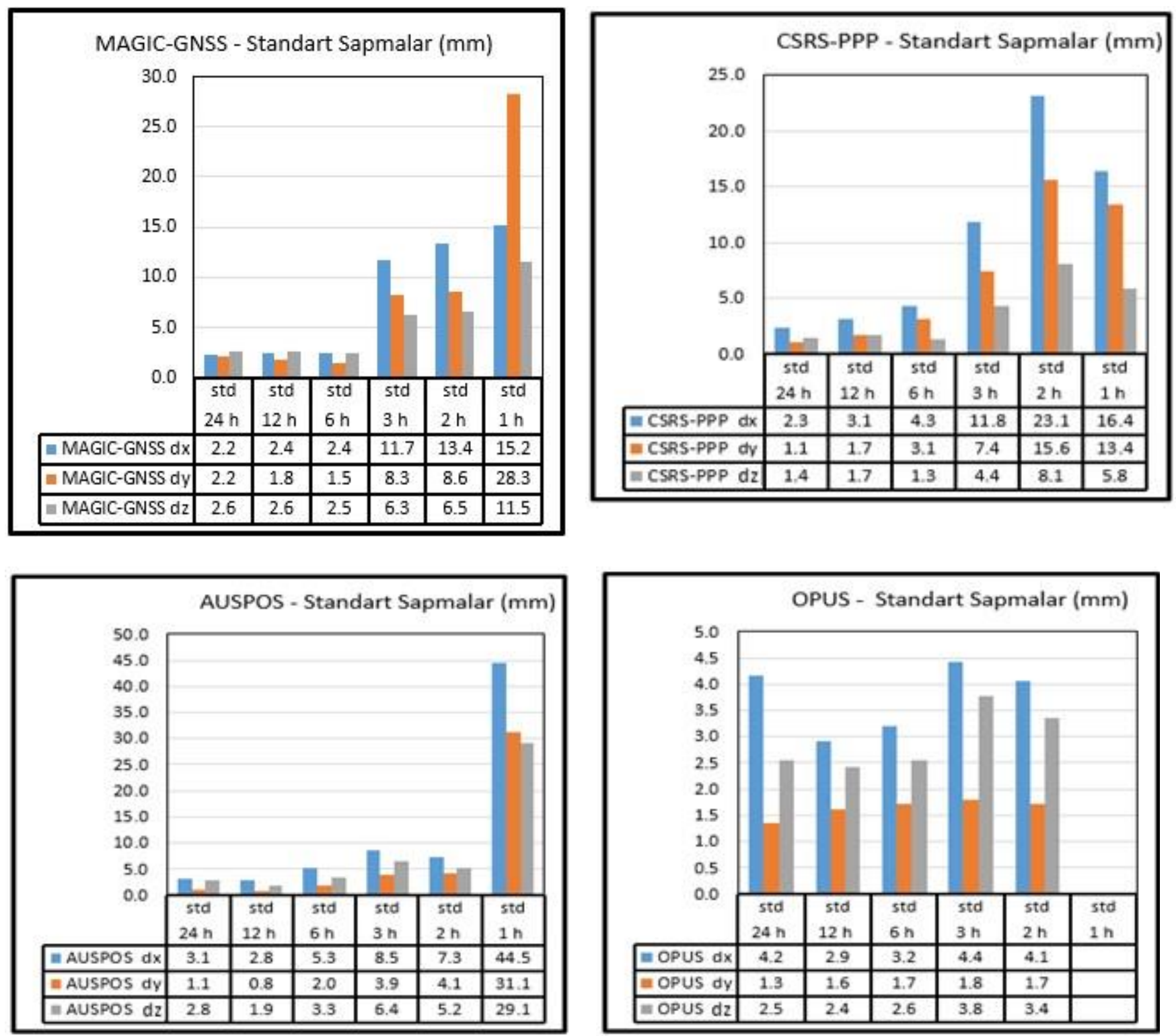

Şekil 12. Tüm servislerin zamana göre standart sapma grafikleri $(\mathrm{mm})$

Web tabanlı çevrimiçi değerlendirme servisleri standart sapmalarını gösteren Şekil 13'deki görsele göre 3 saat ve üstü veri analizlerinde servislerin kullanılabilirliği açısından standart sapmalarının oldukça iyi olduğu görülmekte, sonuçların servislerin güvenilirliğini arttırdığını ifade etmek mümkün olmaktadır.

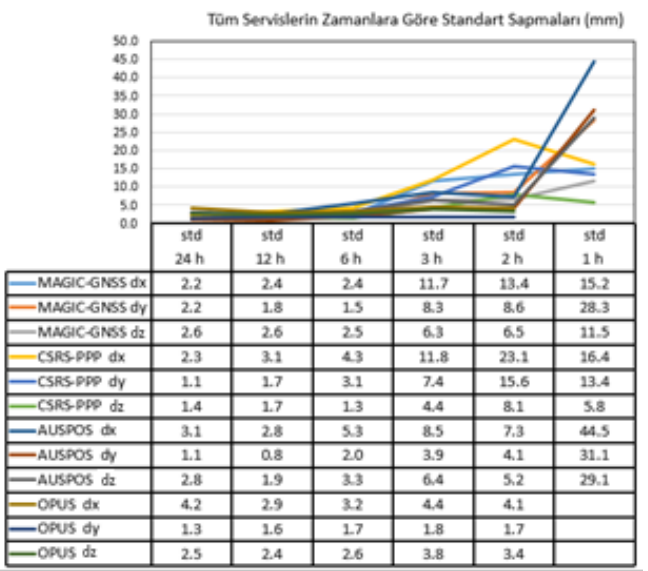

Şekil 13. Tüm servislerin zamana göre standart sapma grafikleri (mm)

\section{SONUÇLAR}

Web-tabanlı GNSS çevrimiçi veri değerlendirme servisleri kullanılarak tek bir alıcı ile yapılan ölçmeler analiz edilebilmekte gerek saha çalışmalarının yükü gerekse maliyetlerin azalması konusunda büyük kolaylıklar sağlamaktadır.

$\mathrm{Bu}$ çalışmada web-tabanlı çevrimiçi servislerden mutlak (PPP) çözüm tekniği kullanan MAGIC-GNSS, CSRS-PPP ve bağıl çözüm tekniklerini kullanan AUSPOS, OPUS servislerini kullanılarak farklı gözlem sürelerindeki $(24(0-24 \mathrm{~h}), 12(0-12 \mathrm{~h}), 6(0-6 \mathrm{~h}), 3(0-3 \mathrm{~h})$, $2(0-2 \mathrm{~h}), 1(0-1 \mathrm{~h})$ saat) IGS servisinin AJAC istasyonunun 7 günlük GNSS verileri analiz edilmiş, servislerin performanslarının ve tekrar edilebilirliğinin belirlenmesi amaçlanmıştır.

Uygulamalar ve bulgulardan görüldüğü üzere 3 saat ve üstü GNSS verilerinin bu servislerde analizi sonucu $\mathrm{mm}$ ve $\mathrm{cm}$ seviyelerinde doğrulukla konum ve yükseklik elde edilebileceği görülmüştür. Bazı günlerdeki veri servisleri çözümlerinde saatlere göre konum doğrulukları her ne kadar mantıksal çelişkiler gösterse de bunun gün bazlı olarak değerlendirildiğinde çelişkinin 
süreklilik göstermediği, servislerin çözüm verilerinde kartezyen koordinatların birim koordinat hataları (tekrarlanabilirlik) verilerine bunun net olarak yansıdığ görülmüștür. Bununla beraber kısa gözlem sürelerinde uydu-alıcı geometrisi, troposfer, iyonosferik etkilerin, manyetik firtınaların etkisi olabildiği bu nedenle gün bazlı atmosferik etkilerin incelenmesi de konum doğruluklarına etki eden hususların incelenmesinde ve yapılacak uygulamanın irdelenmesinde önemli ipucular vermektedir. Ayrıca genele ve ortalamalara bakıldığında ise bu çelişkilerin sistemin tamamında şüphe uyandıracak çoklukta ve farklılıklarda olmadığı gözlemlenmiştir.

Konum doğrulukları açısından veri çözüm yöntemleri incelendiğinde ise Mutlak (PPP) çözüm yöntemi kullanan servislerin konum doğruluklarının yanında bağıl çözüm yöntemi kullanan servislerin de başarılı sonuçlar elde ettiği gözlemlenmiş, 3 saat ve üstü veri çözümlerinde tüm servislerin $\mathrm{mm}$ ve birkaç $\mathrm{cm}$ seviyesinde konum doğrulukları elde ettikleri, servis özelinde incelendiğinde ise özellikle 6 saat ve üstü veri çözümlerinde konum doğrulukları ve tekrar edilebilirliği göz önüne alındığında MAGIC-GNSS ve CSRS-PPP servisi $\mathrm{mm}$ hassasiyetinde benzer sonuçlar üretmiş, AUSPOS servisinin de OPUS servisine nazaran daha başarılı olduğu, bunda da en büyük etkenin AUSPOS servisi analiz sonuçlarında görüldüğü üzere 15 referans IGS istasyonu baz vektör doğruluk verileri ve tam sayı belirsizliği çözüm doğruluk oranlarının oldukça iyi olmasıdır.(OPUS servisi 3 IGS referans istasyonu kullanır.) Bağıl çözüm yönteminde bileșen doğruluğuna oturum süresi yanında, baz mesafesine olan uzaklı̆̆ının da etki ettiği gözlemlenmiştir. Öbür taraftan tüm servislerin kullanıcı açısından kullanabilir ve istenilen doğrulukların elde edilebilir olduğu gözlenmiștir.

Yaklaşık 15 yıldan fazla web-tabanlı çevrimiçi GNSS veri servislerinin aktif olarak kullanıldığı ve her geçen yıl geliştirildiği, yeni sürümlerinin kullanıcıya sunulduğu göz önüne alındığında, servislerin mutlak veya bağıl çözüm yöntemi sunmasının öneminden ziyade kullanıcının ihtiyacının karşılanabilir olması önem arz etmektedir. Veri servislerinin algoritma olarak hata kaynaklarını minimize edecek şekilde geliştirilmesi, çözümlemede kullandığı verilerin doğruluklarının arttırılması sebebiyle sistem kullanılabilirliğinin iyileştiği tartışılmaz bir gerçektir. Servisler çoğunlukla birbirlerinden farklı değerlendirme yöntemleri kullanmaktadır. Kolay kullanımlı olmasının yanında mutlaka gerekli kontrollerin yapılacağı analizler, farklı günlerde yapılan ölçmeler ile çözümlerin tekrarlanır olduğu gözlenmelidir ki yapılacak çalışmalarda büyük problemlere neden olmasın. Servisler, değerlendirme süreçlerinde her ne kadar kullanıcıya anten yüksekliği, IGS istasyon seçimi gibi bazı seçenekler dışında müdahale yetkisi vermeseler de yazılım bilgisi olmayan kullanıcıya, çift frekanslı bir GNSS alıcısı ile toplanan verinin eș zamanlı ölçülere ihtiyaç olmadan, düșük maliyet ve yüksek doğruluk sağlaması, web-tabanlı çevrimiçi GNSS servislerinin kamu kurumu, mühendislik firmaları ve bilim insanlarına, klasik yöntemlerin yanında önemli bir alternatif olarak büyük yarar sağlayacaktır.

\section{BILLGILENDİRME/TEŞEKKÜR}

$\mathrm{Bu}$ çalıșmada veri olarak kullanılan IGS ürünlerinden dolayı IGS servisine, analizlerde kullanılan web tabanlı çevrimiçi servislerinden MAGIC-GNSS için GMV Innovation Solutions'a, CSRS-PPP için Natural Resources Canada (NRCan), Geodetic Survey Division'a, AUSPOS için Geoscience Australia'ya ve OPUS için National Geodetic Survey'e teșekkür ederim.

\section{ÇATIŞMA BEYANI}

Herhangi bir çıkar çatışması bulunmamaktadır.

\section{KAYNAKÇA}

Alçay S \& İmren H (2017). Opus ve Auspos Web-Tabanlı GPS Değerlendirme Servislerinin Farklı Gözlem Süreleri İçin Doğruluk Performanslarının İncelenmesi. Ömer Halisdemir Üniversitesi Mühendislik Bilimleri Dergisi. 6. 452-466. 10.28948/ngumuh.341282.

Alkan R \& Ozulu I M \& ilçi V (2017). Klasik GNSS Veri Değerlendirme Yazılımlarına Alternatif Olarak Webtabanlı Online Değerlendirme Servisleri /// Web-based Online Data Processing Services as an Alternative to Conventional GNSS Processing Software. 17. 603-619. 10.5578/fmbd.57600.

Bisnath S \& Gao Y (2007). Current State of Precise Point Positioning and Future Prospects and Limitations, Proceedings of Observing our Changing Earth. IAG Symopsium Series, 133, 615-624.

Cleaver B L (2013). Evaluation of the performance of web-based GNSS post processing systems. Dissertação, University of Southern Queensland.

Gao Y \& Shen X (2002). A New Method For CarrierPhase-Based Precise Point Positioning. Navigation: Journal of Institute of Navigation, 49(2), 109-116

Gillins D T, Kerr D \& Weaver B (2019). "Evaluation of the Online Positioning User Service for Processing Static GPS Surveys: OPUS-Projects, OPUS-S, OPUS-Net, and OPUS-RS," ASCE Journal of Surveying Engineering, 145(3): 05019002.

Kouba J \& Héroux P (2001). Precise Point Positioning Using IGS Orbit and Clock Products. GPS Solutions 5, 12-28. https://doi.org/10.1007/PL00012883

Li X \& Zhang X (2012). Improving the Estimation of Uncalibrated Fractional Phase Offsets for PPP Ambiguity Resolution. The Journal of Navigation, 65(3), 513-529.

Kouba J (2009). A Guide to Using International GNSS Service (IGS) Products. IGS Central Bureau, http:// igscb.jpl.nasa.gov/components/usage.html), May 2009.

Ocalan T, Erdogan B \& Tunalıglu N (2013). Analysis of web-based Online Services For GPS Relative And Precise Point Positioning, Bol. Ciênc. Geod., sec. Artigos, Curitiba, 19(2): 191207

Ocalan T (2016). Accuracy assessment of GPS precise point Positioning (PPP) technique using different 
web-based online services in a forest environment. 140. 357-368.

Özdemir E G, Gülal V E (2019). İnternet Tabanlı Hassas Nokta Konum Belirleme (PPP) Yazılımlarının İrdelenmesi ve Belirsizlik Analizi, 17. Türkiye Harita Bilimsel ve Teknik Kurultayı, Ankara.

Pı́riz R, Calle D, Mozo A, Navarro P, Rodriguez D, Tobias G (2009). Orbits and clocks for GLONASS precisepoint-positioning In Proc. ION/ GNSS 22th

Int. Technical Meeting of the Satellite Division, Savannah, Georgia, USA, 2415-2424.

Rizos C (2010), Making sense of the GNSS techniques, Chap 11 in Bossler J, Campbell JB, McMaster R, Rizos C (Eds) Manual of Geospatial Science and Technology, 2nd edition, Taylor \& Francis, ISBN 978-1-42008733-8,173-190.

Sezer G \& Dogan A H \& Erdogan B (2021). Çoklu-GNSS çözümlerinin performansının internet tabanlı Trimble RTX servisi ile incelenmesi. Journal of Geodesy and Geoinformation. 8. 30-40. 10.9733/JGG.2021R0003.T.

Şimşek M, Özarpacı S, Doğan U (2019). Yer Kabuğu Hareketlerinin Belirlenmesinde Web Tabanl Çevrimiçi GNSS Servislerinin Performans Analizi. Geomatik, 4 (2), 147-159.DOI: 10.29128/geomatik.511758

Tsakiri M (2008). GPS Processing Using Online Services. Journal of Surveying Engineering, 134(4), 115-125. https://doi.org/10.1061/(ASCE)07339453(2008)134:4(115).
Weston N D \& Schwieger V (2010). Cost Effective GNSS Positioning Techniques. FIG Commission 5 Publications, No. 49.

Zumberge J F, Heflin M B, Jefferson D C, Watkins M M \& Webb F H (1997). Precise point positioning for the efficient and robust analysis of GPS data from large networks, J. Geophys. Res.,102(B3), 5005- 5017, doi:10.1029/96JB03860.

URL-1: https://geodesy.noaa.gov/OPUS/about.jsp\#about Erişim Zamanı: 09 Ekim 2020

URL-2:

http://www.igs.org/igsnetwork/network_by_site.ph p?site=ajac Erişim Zamanı: 09 Ekim 2020

URL-3:

https://www.gfz-potsdam.de/kp-index/

Erişim Zamanı: 01 Ocak 2021

URL-4: MAGIC-GNSS Web Sayfası

http://magicgnss.gmv.com

Erişim Zamanı: 09 Ekim 2020

URL-5: CSRS-PPP Web sayfası

https://webapp.geod.nrcan.gc.ca/geod/toolsoutils/ppp.php Erişim Zamanı: 09 Ekim 2020

URL-6: AUSPOS Web Sayfası

https://gnss.ga.gov.au/auspos

Erişim Zamanı: 09 Ekim 2020

URL-7: OPUS Web Sayfası

https://www.ngs.noaa.gov/OPUS/

Erişim Zamanı: 09 Ekim 2020 